\title{
Comparação dos Métodos para Diagnóstico da Toxoplasmose Congênita
}

\author{
A Comparison between Methods for the Diagnosis of Congenital Toxoplasmosis
}

Flávia Cipriano Castro, Mário Jorge Barreto Viegas Castro, Antônio Carlos Vieira Cabral, Geraldo Brasileiro Filho, Ricardo Wagner de Almeida Vitor, Ana Maria Arruda Lana, Gláucia Manzan Queiroz de Andrade.

\begin{abstract}
RESUMO
Objetivo: avaliar a eficácia da reação em cadeia da polimerase (PCR) no líquido amniótico para a detecção da contaminação fetal pelo Toxoplasma gondii em gestantes com infecção aguda e correlacionar com a técnica de inoculação e a histologia da placenta.

Métodos: trinta e sete pacientes foram estudadas prospectivamente e o diagnóstico foi baseado na identificação da infecção aguda materna, seguido pela amniocentese guiada pela ultrasonografia para obtenção de líquido amniótico para a realização de PCR e inoculação em camundongo. As pacientes foram tratadas com espiramicina durante a gestação; se a infecção fetal era demonstrada, pirimetamina e sulfadiazina eram acrescentadas ao esquema. As placentas foram encaminhadas para exame histológico. As crianças foram acompanhadas durante um periodo que variou de três a 23 meses para a confirmação ou exclusão da toxoplasmose congênita.

Resultados: medidas de associação como sensibilidade, especificidade e valores preditivos foram calculadas para a PCR no líquido amniótico, a inoculação em camundongo e a histologia da placenta, mostrando os seguintes resultados: para a PCR, uma sensibilidade de 66,7\% e especificidade de 87,1\%; os respectivos valores para a inoculação em camundongo foram 50 e $100 \%$ e para a histologia da placenta foram 80 e 66,7\%.

Conclusões: embora a PCR não deva ser utilizada isoladamente para diagnóstico de toxoplasmose congênita, é um método promissor e necessita de maiores estudos para melhorar sua eficácia.
\end{abstract}

PALAVRAS-CHAVE: Toxoplasmose congênita. Diagnóstico pré-natal. Reação em cadeia da polimerase.

\section{Introdução}

A infecção materna primária com Toxoplasma gondii adquirida durante a gestação ainda é de elevada importância em nosso meio pelo fato de poder resultar em infecção fetal com graves seqüelas para a criança ${ }^{1}$. O espectro clínico da infecção congênita pelo T. gondii varia de alterações aparentes ao nascimento com morbimortalidade perinatal elevada (microcefalia, crescimento intra-uterino re-

Centro de Medicina Fetal do Hospital das Clínicas da Universidade Federal de Minas Gerais

Correspondência:

Flávia Cipriano Castro

Rua Timbiras, 2774/404 - Bairro Barro Preto

30140.062 - Belo Horizonte - MG

Telefone: (31) 3335-5498 tardado, hidrocefalia) a uma infecção subclínica com possibilidade de risco para o desenvolvimento de coriorretinite e/ou complicações tardias na vida futura (hidrocefalia) ${ }^{2-5}$.

O diagnóstico precoce assim como o tratamento antiparasitário adequado da mãe tem demonstrado ser capaz de reduzir a taxa de transmissão para o feto e por conseqüência o número de seqüelas nos casos em que a infecção intrauterina já ocorreu ${ }^{6,7}$.

A taxa de transmissão materno-fetal varia principalmente de acordo com a idade gestacional no momento da infecção materna. Quando esta ocorre antes da décima quinta semana de gestação, pode resultar numa taxa de transmissão menor do que $5 \%$, podendo atingir $80 \%$, se próximo do termo ${ }^{8}$, mas o acompanhamento sorológico mater- 
no sistemático durante a gestação permite apenas uma estimativa indireta do risco de infecção fetal $^{9}$.

A fim de providenciar tratamento apropriado para todas as crianças com risco de embriopatia pelo toxoplasma, diagnóstico definitivo da infecção congênita é obrigatório e deve ser prontamente realizado ${ }^{9,10}$. Todas as gestantes suscetiveis à infecção devem ser acompanhadas com testes sorológicos ao longo da gestação e orientadas sobre as situações de risco para adquirir a infecção.

Os testes convencionais para o estabelecimento do diagnóstico fetal da toxoplasmose incluem a identificação direta do parasita ou a inoculação de líquido amniótico em camundongo assim como em cultura de células e, apesar de apresentarem uma boa especificidade, requerem maior tempo para a obtenção do resultado e demonstram baixa sensibilidade ${ }^{6,11,12}$.

O quadro anatomopatológico da placenta na toxoplasmose, como em outras infecções hematogênicas, é caracterizado pela vilosite, em geral focal. Entretanto, é freqüente o comprometimento inflamatório das membranas da placa corial e extra-placentárias. A identificação dos parasitas livres ou encistados pode ser dificil, exigindo a utilização da imuno-histoquímica ${ }^{13}$.

Recentemente, vários estudos têm utilizado a reação em cadeia da polimerase (PCR) para a detecção do ácido desoxirribonucléico (DNA) do $T$. gondii no líquido amniótico sendo atribuída a este método grande acuidade e resposta mais rápida, possibilitando um diagnóstico precoce ${ }^{14-18}$.

Neste estudo, descrevemos os resultados da PCR realizada no líquido amniótico obtido por amniocentese em gestantes com diagnóstico clínico de infecção aguda pelo $T$. gondii e confrontamos estes com os resultados obtidos com a inoculação de líquido amniótico, em camundongo, os achados anatomopatológicos da placenta e dados correspondentes ao acompanhamento pediátrico durante o primeiro ano de vida.

\section{Pacientes e Métodos}

Durante o período compreendido entre janeiro de 1997 e março de 1999, foram acompanhadas no Centro de Medicina Fetal do HC-UFMG 37 pacientes encaminhadas ao pré-natal por apresentarem exame sorológico de rotina para toxoplasmose compatível com infecção aguda (presença de IgM positiva ou surgimento de IgG em pacientes anteriormente soronegativas).

A todas as gestantes foi prescrito espiramicina na dose de $3 \mathrm{~g} /$ dia a partir da con- firmação da infecção materna até o final da gestação. Nos casos de suspeita ultra-sonográfica de comprometimento fetal ou resultado positivo da PCR, foram introduzidos pirimetamina $(50 \mathrm{mg} / \mathrm{dia})$, sulfadiazina ( $3 \mathrm{~g} /$ dia) e ácido folínico (5 $\mathrm{mg} /$ dia) em ciclos de 21 dias alternados com a espiramicina até a 36 ${ }^{a}$ semana de gestação. A partir da 36 - semana utilizou-se a espiramicina até o parto.

A amniocentese guiada por ultra-som foi realizada entre a 20 e a 38 ${ }^{a}$ semana de gestação. Após a identificação do feto e placenta, foi localizado um bolsão, realizada anti-sepsia e anestesia local, puncionada a cavidade amniótica com agulha BD 20 "gauge" de $15 \mathrm{~cm}$ e obtidos $20 \mathrm{~mL}$ de líquido amniótico, que foram retirados e encaminhados para a pesquisa do DNA do parasita por meio da PCR no Laboratório de Biologia Molecular do Departamento de Anatomia Patológica da FMUFMG. Na seqüência, mais 2 a $5 \mathrm{~mL}$ foram obtidos para a inoculação em camundongo no Laboratório de Parasitologia do Instituto de Ciências Biológicas - UFMG.

Após o parto as placentas foram encaminhadas para estudo anatomopatológico. Foram examinadas macroscopicamente de acordo com a técnica preconizada por Benirschke e Driscoll ${ }^{19}$. Após o exame, eram fixadas inteiras em solução de formol a $10 \%$ e, cerca de 24 a 48 horas depois, cortadas em fatias e refixadas. Em seguida, eram retirados fragmentos - três do disco placentário, em toda a sua espessura, dois do cordão umbilical e um do enrolado das membranas. Os fragmentos foram processados como de rotina e os cortes histológicos corados pela hematoxilina-eosina.

Nos casos em que foram encontradas lesões inflamatórias (vilosite), utilizou-se ainda método imuno-histoquímico (streptavidina-biotinaperoxidase) para a identificação de antígeno do $T$. gondii. As alterações anatomopatológicas valorizadas no diagnóstico foram aquelas de natureza inflamatória e/ou a presença de taquizoítos e cistos parasitários.

A avaliação laboratorial das crianças foi realizada no Laboratório Central do Hospital das Clínicas da UFMG e a avaliação clínica realizada no Centro de Referência e Treinamento Orestes Diniz, do setor de Infectologia Pediátrica do HCUFMG. No recém-nascido foi realizado um exame clínico que incluiu pesquisa de IgM específica no sangue de cordão, exames clínico e neurológico, RX de crânio, ultra-sonografia transfontanela, fundoscopia, punção lombar, hemograma e exames de função hepática. Todos os recém-nascidos foram tratados independentemente do diagnóstico pré-natal até a confirmação (evidência clínica, elevação de IgG ou surgimento de IgM) ou exclu- 
são (negativação da sorologia) da infecção. As crianças foram reavaliadas no primeiro, segundo, terceiro, sexto e nono mês de vida. Após o primeiro ano, nos casos confirmados, foram repetidos a sorologia específica, RX de crânio, fundoscopia e exames clínico e neurológico.

Foi obtido o consentimento pós-informação de cada paciente participante da pesquisa, sendo o estudo aprovado pela Comissão de Ética da Instituição.

\section{Resultados}

No total foram realizadas 37 amniocenteses para obtenção de líquido amniótico e posterior realização da PCR. Verificou-se que de um total de oito recém-nascidos cujos resultados da PCR foram positivos, quatro tiveram o diagnóstico de infecção congênita confirmado, por meio do exa- me clínico e/ou do acompanhamento sorológico.

Trinta e duas amostras (86\%) de líquido amniótico foram inoculadas em camundongo. Embora esse exame tenha demonstrado uma sensibilidade menor que a da PCR (50\%), não foram observados resultados falso-positivos, configurando uma elevada especificidade ao método (100\%).

Um total de 23 placentas $(60 \%)$ foram examinadas, das quais dez apresentaram alterações anatomopatológicas compativeis com infecção pelo T. gondii. Em quatro casos o diagnóstico de infecção congênita foi confirmado por meio do estudo clínico-laboratorial do recém-nascido após o nascimento.

As 37 crianças foram acompanhadas durante um período que variou de três a 23 meses. Em seis recém-nascidos $(16,2 \%)$ pôde-se confirmar a presença de infecção fetal (Tabela 1). As 31 crianças restantes apresentaram desenvolvimento neuropsicomotor normal até a época da negativação da sorologia.

\begin{tabular}{|c|c|c|c|c|c|c|c|c|c|c|c|}
\hline $\begin{array}{c}\text { Caso } \\
\mathrm{n}^{0}\end{array}$ & $\begin{array}{c}\text { Tratamento } \\
\text { materno }\end{array}$ & $\begin{array}{l}\text { IG do } \\
\text { parto } \\
\text { (sem.) }\end{array}$ & $\begin{array}{c}\text { Peso ao } \\
\text { nascimento } \\
\text { (g) }\end{array}$ & PCR & $\begin{array}{c}\lg M \\
\text { de cordão }\end{array}$ & $\begin{array}{l}\text { Punção } \\
\text { lombar }\end{array}$ & USTF & $\begin{array}{l}\text { RX de } \\
\text { crânio }\end{array}$ & Fundoscopia & $\begin{array}{c}\text { Tratamento } \\
\text { do RN }\end{array}$ & $\begin{array}{l}\text { Estado } \\
\text { clínico } \\
(1999)\end{array}$ \\
\hline $1^{*}$ & Não & 25 & 635 & + & NR & NR & NR & NR & NR & NR & Necrópsia \\
\hline 2 & Regular & 37 & 2110 & + & neg & Proteínas & Hidrocefalia & NR & Coriorretinite & Sim & $\begin{array}{c}\text { DVP aos } 2 \\
\text { meses }\end{array}$ \\
\hline 3 & Regular & 39 & 3190 & + & neg & $N R$ & NR & Calcificações & Normal & Sim & $\begin{array}{c}11 \text { meses/ } \\
\lg \mathrm{G}+\end{array}$ \\
\hline 4 & Não & 39 & 3080 & + & neg & $N R$ & NR & Normal & Normal & Sim & $\begin{array}{l}23 \text { meses/ } \\
\text { lgG e lgM + }\end{array}$ \\
\hline 5 & Não & 38 & 2835 & - & NR & Proteínas & Hidrocefalia & Calcificações & Coriorretinite & Sim & $\begin{array}{l}\text { Óbito com } \\
19 \text { dias. } \\
\text { Toxoplasmose } \\
\text { congênita } \\
\text { grave }\end{array}$ \\
\hline 6 & Não & 35 & 1100 & - & neg & Normal & Hidrocefalia & NR & Normal & Sim & $\begin{array}{l}3 \text { meses/ } \\
\text { CIUR grave }\end{array}$ \\
\hline
\end{tabular}

* Necrópsia: coriorretinite, encefalite toxoplásmica e ventriculomegalia

$\mathrm{NR}$ = não realizado; DVP = derivação ventrículo-peritoneal; neg = negativo; USTF = ultra-som transfontanela; CIUR = crescimento intra-uterino restrito.

Entre os oito casos nos quais a PCR foi positiva (Tabela 2), o diagnóstico pós-natal confirmou quatro e excluiu a doença em outros quatro. A inoculação de líquido amniótico em camundongo foi positiva em dois casos, dos quais em um a $\mathrm{PCR}$ foi negativa. O exame anatomopatológico da placenta foi alterado em dez casos, sendo concordante com a PCR em quatro. Esse exame também confirmou a presença de toxoplasmose congênita em dois casos cujo resultado da PCR foi negativa.

O cálculo da concordância dos testes diag- nósticos não foi possivel devido ao pequeno tamanho da amostra.

\section{Discussão}

O presente trabalho refere-se ao acompanhamento de 37 gestações envolvendo a toxoplasmose materna, nas quais o diagnóstico da infecção congênita foi definitivamente estabelecido ou excluído após o parto. 
Tabela 2 - Idade gestacional quando do diagnóstico da infecção materna, início do tratamento e dados dos RNs de pacientes com resultados de PCR positivos.

\begin{tabular}{|c|c|c|c|c|}
\hline Casos & $\begin{array}{l}\text { IG - infecção } \\
\text { materna (sem.) }\end{array}$ & $\begin{array}{l}\text { IG - início do } \\
\text { tratamento (sem.) }\end{array}$ & $\begin{array}{l}\text { Sinais de infecção } \\
\text { ao nascimento }\end{array}$ & Evolução \\
\hline 1 & 8 & 32 (regular) & Nenhum & TC descartada - 7 meses negativação lgG \\
\hline 2 & 15 & 27 (regular) & Nenhum & TC descartada - 12 meses \\
\hline 3 & 4 & não utilizou & Nenhum & TC descartada - 7 meses \\
\hline 4 & 12 & 26 (irregular) & Nenhum & TC descartada - 6 meses \\
\hline 5 & 15 & não utilizou & Neomorto & $\begin{array}{l}\text { Necrópsia; coriorretinite, encefalite } \\
\text { toxoplásmica, ventriculomegalia }\end{array}$ \\
\hline 6 & 15 & 18 (regular) & $\begin{array}{l}\text { Hidrocefalia; coriorretinite; } \\
\text { proteinorraquia }\end{array}$ & DVP aos 2 meses \\
\hline 7 & 16 & 27 (regular) & Calcificações cerebrais & 11 meses/lgG positivo \\
\hline 8 & 18 & não utilizou & Nenhum & $\begin{array}{c}23 \text { meses lgG e lgM positivos/exame clínico } \\
\text { normal }\end{array}$ \\
\hline
\end{tabular}

IG = idade gestacional; $R N=$ recém-nascido; $P C R$ = reação em cadeia da polimerase; $\mathrm{TC}=$ toxoplasmose congênita; DVP = derivação ventrículo-peritoneal

Neste estudo observou-se uma incidência de toxoplasmose congênita de $16,2 \%$ em um grupo de gestantes com infecção aguda e uma taxa de infecção subclínica de 16,6\%. Esses dados revelam que a falta de uma triagem sorológica de rotina em nosso meio não apenas dificulta o diagnóstico de toxoplasmose aguda na gestação, como também pode ser responsável por um aumento na incidência de infecção fetal clinicamente aparente, uma vez que o diagnóstico pré-natal passa a ser realizado mais tardiamente, a partir de alterações fetais detectadas, em geral, ao exame ultrasonográfico. Este fato por si só demonstra a importância do rastreamento desta doença nas pacientes obstétricas.

Na literatura, a sensibilidade da PCR para o diagnóstico da toxoplasmose congênita variou de 70 a $100 \%{ }^{14,17,20,21}$ contra $66,7 \%$ obtido neste estudo. Atribuímos essa menor sensibilidade a dois resultados falso-negativos. No primeiro deles, a paciente foi encaminhada com 34 semanas ao serviço, apresentando à ultra-sonografia hidrocefalia bilateral assimétrica associada à suspeita de calcificações hepáticas. Durante a realização da amniocentese houve contaminação do líquido amniótico com sangue. O resultado da PCR foi negativo. No acompanhamento pós-natal confirmou-se o diagnóstico de toxoplasmose congênita grave com acometimento de múltiplos órgãos, sendo que a criança evoluiu para o óbito com 19 dias de vida.

No segundo caso o feto apresentava à ultrasonografia realizada com 21 semanas uma assimetria de ventrículos laterais e crescimento intra-uterino retardado. A amniocentese ocorreu sem intercorrências e o resultado da PCR não revelou contaminação fetal. O diagnóstico de toxoplasmose congênita foi realizado ao nascimen- to.

Existem algumas explicações para esses resultados. A sensibilidade da técnica em espécimes clínicos pode ser influenciada pela grande quantidade de células e de DNA humano, os quais podem interferir na reação ${ }^{22}$, e, sobretudo, por fatores inibidores da Taq DNA polimerase, como as porfirinas em amostras que contenham sangue ${ }^{23}$. Grover et al. ${ }^{21}$ propõem, nos casos de contaminação do líquido amniótico com sangue, o tratamento da amostra com o objetivo de diminuir essa contaminação ${ }^{21}$. Na tentativa de eliminar esses fatores, as amostras foram submetidas a novo processo de extração (fenol-clorofórmio), que consegue separar com mais eficiência o DNA das proteínas presentes ${ }^{24}$.

As explicações para o resultado falso-negativo ocorrido no segundo caso são mais complexas. Segundo Daffos et al. ${ }^{25}$ uma provável causa de resultados falso-negativos ocorreria devido a uma transmissão mais tardia do parasita ao feto, posterior à realização da PCR, apesar do tratamento com a espiramicina ${ }^{25}$. Essa hipótese torna-se pouco provável neste estudo, uma vez que ambos os fetos apresentavam, no momento da realização da amniocentese, alterações ecográficas compativeis com toxoplasmose congênita.

Segundo Grover et al. ${ }^{21}$ os primers utilizados podem não ter sido capazes de amplificar o gene B1 contido na amostra. Para contornar esse problema, um controle de qualidade deve ser instituido, testando-se o primer em outras cepas de Toxoplasma gondii ou substituindo-o por outro capaz de detectar o gene B1.

Outra hipótese possivel seria a ausência do gene B1 na cepa do Toxoplasma gondii em estudo. Uma solução para esse caso seria a utilização de primers contendo outros antígenos do parasita 
(como P30 e 18S). No entanto, do ponto de vista prático, torna-se pouco acessivel pois, para cada antígeno, os procedimentos a serem executados são diferentes.

Para o segundo caso, quaisquer das demais hipóteses citadas são válidas. Após esses resultados, adotou-se como rotina no laboratório a repetição da PCR na mesma amostra, em casos discordantes como os referidos, conforme proposto por Derouin et al. ${ }^{22}$ que mostraram que a repetição seriada de várias PCRs em uma mesma amostra e a utilização de alvos repetitivos aumenta a sensibilidade do exame.

Neste estudo foram encontrados quatro resultados falso-positivos (especificidade de $87 \%$ ). No nosso meio esta técnica vem sendo utilizada há pouco tempo, sendo este estudo pioneiro no Estado de Minas Gerais. Dessa forma, atribuímos a elevada taxa de falso-positivos encontrada à contaminação da reação em alguma etapa do processo. Outros autores como Cazenave et al. ${ }^{17}$, Grover et al. ${ }^{21}$ e Kwok e Higuchi ${ }^{26}$ também atribuem os resultados falsos-positivos a problemas na realização da técnica da PCR.

O isolamento do parasita não foi bem sucedido em todas as amostras neste estudo. Acreditamos que um dos fatores possivelmente responsáveis por este fato estaria no número pequeno de pacientes testadas, uma vez que, em pequenas amostras, cada resultado falso-negativo contribuiria para uma redução significativa na sensibilidade do teste; outro fator decorreria da parasitemia poder ser intermitente, não coincidindo com o momento da coleta.

Dos dois resultados de inoculação de líquido amniótico em camundongo positivos observados neste estudo, ambos foram confirmados no periodo pós-natal e, em apenas um caso, o resultado da PCR foi positivo. Esses dados confirmam os resultados da literatura, que indicam que no diagnóstico antenatal de toxoplasmose congênita deve-se utilizar concomitantemente o método da PCR no líquido amniótico e a inoculação deste em camundongo, pelo fato de o primeiro apresentar melhor sensibilidade $(66,7 \%)$ e baixo valor preditivo positivo $(50 \%)$ e o segundo ter excelente especificidade $(100 \%)$, assim como um valor preditivo positivo também de $100 \%$.

Em apenas um caso com PCR positivo e/ou sinais de transmissão congênita não foram encontradas lesões inflamatórias na placenta. Tal fato pode ser atribuído à amostragem relativamente escassa que se faz de rotina (três fragmentos de um órgão de grande proporção).

Parasitismo pode ser evidenciado apenas à imuno-histoquímica em casos de infecção recen$t^{13}$. Também existe o fato de que o tratamento possa ter influenciado na dificuldade do encontro de parasitas. Segundo Valente e $\mathrm{Sever}^{27}$, a freqüência do isolamento é reduzida se a mulher é tratada com espiramicina, pirimetamina ou sulfadiazina durante a gestação.

Baseando-se nesses resultados, concluiu-se que o exame anatomopatológico da placenta no diagnóstico pós-natal, quando não apresenta qualquer alteração histopatológica, ajuda a descartar a possibilidade de doença, porém, achados histopatológicos positivos não são confiáveis para a confirmação da doença.

O diagnóstico pré-natal é de importância fundamental no acompanhamento de uma gestante com toxoplasmose aguda. No entanto, no nosso meio, o método da PCR no líquido amniótico para diagnóstico antenatal de toxoplasmose congênita ainda apresenta dificuldades técnicas, não devendo ser utilizada, isoladamente, na prática clínica.

Acredita-se que a viabilização das soluções mencionadas, bem como o aperfeiçoamento e o melhor conhecimento dessa técnica, permitirão, em um futuro próximo, a diminuição dos resultados discordantes e sua ampla utilização.

\section{SUMMARY}

Objective: to test the effectiveness of the polymerase chain reaction (PCR) in the amniotic fluid for the detection of fetal contamination due to Toxoplasma gondii in pregnant women with acute infection and to correlate it with the inoculation technique and the histology of the placenta.

Methods: thirty-seven patients were prospectively studied and the diagnosis was based on the identification of maternal acute infection followed by amniocentesis guided by ultrasound to obtain amniotic fluid for PCR and mice inoculation. The mothers were treated with spiramycin throughout pregnancy; when fetal infection was demonstrated, pyrimethamine and sulfadiazine were added to the regimen. The placentas were processed for histologic examination. The infants were followed for a period that varied from three to 23 months for the confirmation or exclusion of congenital toxoplasmosis.

Results: association measures such as sensitivity, specificity and predictive values were calculated for PCR in the amniotic fluid, detection of the parasite through mice inoculation and placental histology and showed the following results: $P C R$ values of sensitivity $=66.7 \%$ and specificity $=87.1 \%$; the respective values for mice inoculation were 50 and $100 \%$ and for the placental histology were 80 and $66.7 \%$.

Conclusion: although PCR should not be used alone for the prenatal diagnosis of congenital toxoplasmosis, it is a promising method and deserves more studies to improve its efficacy. 
KEY WORDS: Congenital toxoplasmosis. Prenatal diagnosis. Polymerase chain reaction.

\section{Referências}

1. Stray-Pedersen B. Toxoplasmosis in pregnancy. Baillieres Clin Obstet Gynaecol 1993; 7:107-37.

2. Koppe JG, Loewer-Sieger DH, de Roever-Bonnet H. Results of 20-year follow-up of congenital toxoplasmosis. Lancet 1986; 1:254-6.

3. Wilson CB, Remington JS, Stagno S, Reynolds DW. Development of adverse sequelae in children born with subclinical congenital Toxoplasma infection. Pediatrics 1980; 66:767-74.

4. McAuley J, Boyer KM, Patel D, et al. Early and longitudinal evaluations of treated infants and children and untreated historical patients with congenital toxoplasmosis: the Chicago collaborative treatment trial. Clin Infect Dis 1994; 18:38-72.

5. Roizen N, Swisher CN, Stein MA, et al. Neurologic and developmental outcome in treated congenital toxoplasmosis. Pediatrics 1995; 95:11-20.

6. Hohlfeld P, Daffos F, Thulliez P, et al. Fetal toxoplasmosis outcome of pregnancy and infant follow-up after in utero treatment. J Pediatr 1989; 115:765-9.

7. Foulon W, Naessens A, Derde MP. Evaluation of the possibilities for preventing congenital toxoplasmosis. Am J Perinatol 1994; 11:57-62.

8. Foulon W, Villena I, Stray-Pedersen B, et al. Treatment of toxoplasmosis during pregnancy: a multicenter study impact on fetal transmission and children sequelae at age 1 year. Am J Obstet Gynecol 1999; 180:410-5.

9. Remington JS, McLeod R, Desmonts G. Toxoplasmosis. In: Remington JS, Klein JO, editors. Infectious Diseases of the Fetus and the Newborn Infant. $4^{\text {th }}$ ed. Philadelphia: W.B. Saunders; 1995. p.140-267.

10.Lebech M, Joynson DH, Seitz HM, et al. Classification system and case definitions of Toxoplasma gondii infection in immunocompetent pregnant women and their congenitally infected offspring. Eur J Clin Microbiol Infect Dis 1996; 15:799-805.

11.Abboud P, Villena I, Chemla C, et al. Dépistage de la toxoplasmose congénitale: devenir des grossesses après le diagnostic anténatal. A propos de 211 cas. J Gynecol Obstet Biol Reprod (Paris) 1997; 26:40-6.

12.Dorangeon $\mathrm{P}$, Fay R, Marx-Chemla C, et al. Passage transplacentaire de l'association pyriméthaminesulfadoxine lors du traitement anténatal de la toxoplasmose congénitale. Presse Med 1990; 19:2036.

13.Bittencourt AL. Infecções congênitas transplacentárias. $1^{\mathrm{a}}$ ed. Rio de Janeiro: Revinter; 1995. p.196.

14.Hohlfeld P, Daffos F, Costa JM, Thulliez P, Forestier F, Vidaud M. Prenatal diagnosis of congenital toxoplasmosis with a polymerase-chain-reaction test on amniotic fluid. N Engl J Med 1994; 331:695-9.

15.Kapperud G, Jenum PA, Stray-Pedersen B, Melby KK, Eskild A, Eng J. Risk factors for Toxoplasma gondii infection in pregnancy: results of a prospective case-control study in Norway. Am J Epidemiol 1996; 144:405-12.

16.Foulon W, Naessens A, Mahler T, de Waele M, de Catte L, de Meuter F. Prenatal diagnosis of congenital toxoplasmosis. Obstet Gynecol 1990; 76:769-72.

17. Cazenave J, Forestier F, Bessieres MH, Broussin $\mathrm{B}$, Begueret J. Contribution of new PCR assay to the prenatal diagnosis of congenital toxoplasmosis. Prenat Diagn 1992; 12:119-27.

18.Forestier F, Hohlfeld P, Sole Y, Daffos F. Prenatal diagnosis of congenital toxoplasmosis by PCR: extended experience. Prenat Diagn 1998; 18:4079.

19.Benirschke K, Driscoll SG. The pathology of human placenta. $1^{a}$ ed. New York: Springer-Verlag; 1967. p.512.

20.Dupouy-Camet J, Bougnoux ME, Lavareda de Souza $\mathrm{S}$. Comparative value of polymerase chain reaction and conventional biological tests for the prenatal diagnosis of congenital toxoplasmosis. Ann Biol Clin (Paris) 1992; 50:315-9.

21.Grover CM, Thulliez P, Remington JS, Boothroyd JC. Rapid prenatal diagnosis of congenital infection by using polymerase chain reaction and amniotic fluid. J Clin Microbiol 1990; 28:2297-301.

22.Derouin F, Paugam A, Dupouy-Camet J, Candolfi E. Actualités du diagnostic de la toxoplasmose. Schweiz Med Wochenschr Suppl 1995; 65:52S-61S.

23.Beutler E, Gelbart T, Kuhl W. Interference of heparin with the polymerase chain reaction. Biiotechnigues 1990; 9:166.

24.Teixeira PV. Diagnóstico da toxoplasmose congênita em líquido amniótico através da técnica de PCR [dissertação]. Belo Horizonte: Universidade Federal de Minas Gerais; 2000.

25.Daffos F, Forestier F, Capella-Pavlovsky M, et al. Prenatal management of 746 pregnancies at risk for congenital toxoplasmosis. N Engl J Med 1988; 318:271-5.

26.Kwok S, Higuchi R. Avoiding false positives with PCR. Nature 1989; 339:237-8.

27.Valente $\mathrm{P}$, Sever JL. In utero diagnosis of congenital infections by direct fetal sampling. Isr J Med Sci 1994; 30:414-20. 